\title{
Coupled thermal-structural modelling and experimental validation of spiral mandrel die
}

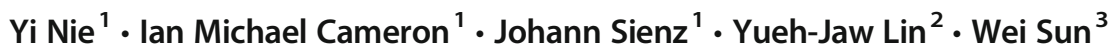

Received: 6 May 2020 / Accepted: 25 September 2020 / Published online: 6 November 2020

(C) The Author(s) 2020

\begin{abstract}
The conventional theoretical method to calculate deformations and stress states is only limited to a few cases of simple extrusion dies due to a number of assumptions and simplifications. A coupled thermal-structural modelling framework incorporating finite element method is thus developed and implemented to determine the mechanical performances of the complicated spiral mandrel die, which has a complex geometrical feature of spiral grooves and is exposed to severe conditions of thermal load and high pressure. The steady-state thermal analysis is carried out by mapping the temperature load on the flow channel from previously simulated flow characteristics of polymer melt. The structural analysis takes inputs from both thermal analysis and previously simulated pressure on polymer melt. Both the temperature and pressure loads on flow channel are transferred via the Smart Bucket Surface mapping algorithm. The mechanical properties of the spiral mandrel die are evaluated by analysing the deformation and stress distribution. The experimental validation is conducted to demonstrate the effectiveness of the numerical model. The effects of both structure parameters of the spiral mandrel and processing parameters upon the maximum stress in the die body and the maximum pressure induced deformation at the die orifice are investigated.
\end{abstract}

Keywords Spiral mandrel die $\cdot$ Coupled thermal-structural modelling $\cdot$ Finite element simulation $\cdot$ Pipe extrusion

\section{Introduction}

The spiral mandrel die is a type of extrusion die that enables mass production of tubular polymer products such as tubes, pipes and blown films. It analysed and reported that one advantage of spiral mandrel dies lies in that they can render a uniform thickness, velocity and temperature distribution of the polymer melts upon exit [1]. The other is that it reduces the appearance of weld lines on the extruded products compared with the traditional spider-type extrusion die.

In the extrusion process, complicated and severe thermal load and high pressure normally expose on the die assembly

Yi Nie

yi.nie@swansea.ac.uk

1 Advanced Sustainable Manufacturing Technologies (ASTUTE 2020), Swansea University, Swansea SA1 8EN, UK

2 College of Engineering and Engineering Technology, Northern Illinois University, DeKalb, IL 60115, USA

3 Department of Mechanical, Materials and Manufacturing Engineering, University of Nottingham, Nottingham NG7 2RD, UK
[2]. A high level of temperature gradient or internal pressure directly affects die wear, tool damage and failure as well as deformation of flow channel which altogether result in shorter tool life and poor extrusion accuracy. This is especially true for spiral mandrel dies, which have complex geometrical features such as distributors and spiral grooves [3]. A thorough understanding of the deformation and stress state of the spiral mandrel die is of crucial importance for solving the above problems and design an optimized tool set for polymer extrusion.

It is the die geometry, material properties and processing conditions that primarily determine the deformation and stress state in tool set during extrusion process. The theoretical method, which is the fasted and simplest way, has been applied by Hopmann and Michaeli [4] to determine the deformation and stress state of polymer extrusion dies. However, as a number of assumptions and simplifications applied, the derived deformation and stress are significant deviant from the real values. Therefore, the theoretical method is only restricted to some cases of simple die geometry.

The deformation and stress analysis of die tools have been significantly improved with the development of numerical methods and computer-aided engineering (CAE). Several researchers have employed the finite element (FE) method to 
analyse the elastic deformation of die tools and evaluate its effects on part dimension. Lee et al. [5] conducted the FE analysis and experimental validation for the elastic deformation behaviours of a cold forging die. It was concluded both the elastic strain of tool and the dimensional errors of forged part could be suitably predicted. In order to quantitatively evaluate the dimensional accuracy of the cold formed component, Long [6] sequentially evaluated the material plastic deformation, heat transfer and tool elastic deformation for the entire cold forming process. The more accurate fully coupled FE analysis, which took into account the interaction of melt flow and die body deflection, were then employed by Wang and Smith [7] to predict the flow uniformity in the coat hanger die. Assaad and Geijselaers [8] also applied the fully coupled FE analysis to calculate a flat die deformation in the production of a U-shaped aluminium profile, together with the experimental validation in terms of the extrusion force and angular deflection of the tongue. Kouzilos et al. $[9,10]$ examined the mechanical stresses exerted on the spider leg of the spider type extrusion die by a fully coupled fluid-structure interaction analysis, which was realized with a commercial finite element software, COMSOL Multiphysics. Both the contact stresses along the die-workpiece interface and elastic deformation behaviour of the die in the cold backward extrusion of steel billets have been investigated and numerically by Pepelnjak et al. [11].

Numerical investigations on the stress state and failure probability of die tools have also been conducted. Akhtar and Arif [12] simulated the dynamic stress and strain values of a hot aluminium extrusion die and implemented fatigue damage models for establishing the correlations of die life with process and design parameters. Behrens et al. [13] applied the FE method to calculate the stress state and evaluate the fatigue failure of hot forging tools taking the thermalmechanical condition into account. Ahn et al. [14] predicted the fatigue life of a typical axi-symmetric extrusion die using the elasto-plastic FEM for deformation analysis and linear elastic fracture mechanics for crack problem analysis. Pedersen [15] performed the fully coupled fluid-solid analyses together with self-developed elastic-plastic material behaviour to study the low cycle fatigue of the forward extrusion dies. The univariate linear regression equation of the service life of extrusion forming die was derived by Yang et al. after conducting the numerical simulation of the die wear in each operation cycle [16]. In addition, Lin et al. [17] have optimized the geometry to improve the service life of hot extrusion dies using $\mathrm{FE}$ analysis and updated sequential quadratic programming (SQP) method. Kwan and Wang [18] have integrated FE simulation with response surface method (RSM) for an optimum dimensional geometry of a cold backward extrusion die under predefined stress. Zhao et al. [19] employed the Pareto-based genetic algorithm to perform the multiobjective optimization for porthole extrusion die with the purpose to achieve the uniform velocity distribution and reduce the deflection and maximum stress on the extrusion die. Bingöl et al. [20] and Pepelnjak et al. [11] have also validated the numerical calculations by developing experimental techniques and devices for measuring accurate stresses on die tools.

The focus of this paper is to investigate the deformation and stress state of the spiral mandrel die, where the working loads on its flow channel (fluid-solid interface) are firstly obtained by load mapping algorithm for the accurate coupled thermal-structural modelling. The three-dimensional simulation of the flow pattern of polymer melt through the spiral mandrel die has been carried out in our previous study [21]. Both and temperature and pressure loads on the flow channel are transferred at the fluid-solid interface using the Bucket Surface algorithm. On this basis, a modelling framework for the sequentially coupled thermal-structural analysis of the spiral mandrel die is constructed. A case study is then conducted to investigate the stress and deformation of a spiral mandrel die during the extrusion process. Experimental validation is performed to evaluate the effectiveness of the coupled thermal-structural modelling for spiral mandrel dies.

\section{Modelling framework}

As the polymer extrusion process is related to a stable state over a relatively long time, the steady-state heat transfer and elastic static structural analysis are considered for the coupled thermal-mechanical analysis of the spiral mandrel die.

\subsection{Steady-state thermal analysis}

The temperature distribution of the spiral mandrel die can be calculated according to the following heat transfer function [22]:

$\lambda\left(\frac{\partial^{2} T}{\partial x^{2}}+\frac{\partial^{2} T}{\partial y^{2}}+\frac{\partial^{2} T}{\partial z^{2}}\right)+\dot{q}=0$

where $\dot{q}$ is the heat source, which is assumed to be zero. The die material is regarded as isotropic, and $\lambda$ is the thermal conductivity. $T$ is the temperature.

The boundary conditions that include constant temperature and convection heat transfer on the outer surfaces of the spiral mandrel die are applied as Eqs. (2) and (3), respectively.

$$
\begin{aligned}
& T(x, y, z)=T_{0}(x, y, z) \\
& -\lambda\left(\frac{\partial T}{\partial n}\right)_{w}=\alpha\left(T-T_{f}\right)
\end{aligned}
$$

where $T_{0}(x, y, z)$ is the specified temperature on the die outer surfaces. $\alpha$ is the heat convection coefficient between die 
outer surface and the air. $T_{f}$ is the temperature of the surrounding air.

The calculation of the above differential equation is usually transferred to the functional extremum problem by the calculus of variation. The differential Eq. (1) and boundary Eqs. (2) and (3) for the spiral mandrel die have the equivalent functional equation

$$
\begin{aligned}
J(T)= & \frac{1}{2} \iiint_{V} \lambda\left[\left(\frac{\partial T}{\partial x}\right)^{2}+\left(\frac{\partial T}{\partial y}\right)^{2}+\left(\frac{\partial T}{\partial z}\right)^{2}\right] d V \\
& +\iint_{\Gamma} \alpha\left(\frac{1}{2} T^{2}-T_{f} T\right) d S
\end{aligned}
$$

The first-order variation of the function equation $J(T)$ is set to be 0 as Eq. (5)

$$
\begin{gathered}
\delta J(T)=\iiint_{V} \lambda\left[\frac{\partial T}{\partial x} \delta\left(\frac{\partial T}{\partial x}\right)+\frac{\partial T}{\partial y} \delta\left(\frac{\partial T}{\partial y}\right)+\frac{\partial T}{\partial z} \delta\left(\frac{\partial T}{\partial z}\right)\right] d V \\
+\iint_{\Gamma} \alpha\left(T-T_{f}\right) \delta T d S=0
\end{gathered}
$$

The solution domain is divided into an FE mesh. Then, Eq. (5) can be written as Eq. (6)

$\left[K_{T}\right]\{T\}=\{Q\}$

where $\{T\}$ is the nodal temperature matrix. $\left[K_{T}\right]$ and $\{Q\}$ are the heat transfer matrix and heat flux matrix as Eqs. (7) and (8), respectively.

$$
\begin{aligned}
& {\left[K_{T}\right]=\sum_{e}\left(\iiint_{V^{e}} k\left\{N_{, i}\right\}^{T}\left\{N_{, i}\right\} d V-\iint_{\Gamma^{e}} \alpha T_{f}\{N\}^{T} d S\right)} \\
& \{Q\}=-\sum_{e} \iint_{\Gamma^{e}} \alpha\{N\}^{T} d S
\end{aligned}
$$

where $\{N\}$ is the shape function matrix and $\left\{N_{, i}\right\}$ is described as Eq. (9).

$$
\left\{N_{, i}\right\}=\left(\begin{array}{llll}
\frac{\partial N_{i}}{\partial x_{i}} & \frac{\partial N_{j}}{\partial x_{j}} & \frac{\partial N_{K}}{\partial x_{k}} & \cdots
\end{array}\right)
$$

in which $N_{i}$ is the shape function of an element. Thus, the calculation of the temperature distribution of the spiral mandrel die is transferred to the calculation of Eqs. (6) to (8).

\subsection{Static structural analysis}

A thermoelastic model is used to describe the constitutive relation of the spiral mandrel die, where the total strain array $\{\varepsilon\}$ is taken to be composed of elastic $\{\varepsilon\}_{e}$ and thermal $\{\varepsilon\}_{T}$ parts as below [23].

$\{\varepsilon\}=\{\varepsilon\}_{e}+\{\varepsilon\}_{T}$

The hardening effect of temperature on die material is ignored, and Hooke's law is given by
$\{\sigma\}=[D]\left(\{\varepsilon\}-\{\varepsilon\}_{T}\right)$

where $\{\sigma\}$ is the stress array and $[D]$ is the elastic matrix. As for the thermal strain array $\{\varepsilon\}_{T}$, the temperature change can only lead to normal strain in the isotropic material shown as

$\{\varepsilon\}_{T}=\alpha T\left[\begin{array}{llllll}1 & 1 & 1 & 0 & 0 & 0\end{array}\right]^{T}$

where $\alpha$ denotes the coefficient of thermal expansion of the extrusion die. $T$ is the temperature.

The FE method is applied for the above thermoelastic analysis. The solution domain is divided into FE meshes. The equilibrium equation of the global structure is obtained as Eq. (13) by direct stiffness method.

$[K]\{u\}=[F]+\{R\}_{T}$

where $[K]$ is the global stiffness matrix shown as Eq. (14), $\{u\}$ is the global nodal displacement matrix, $[F]$ is the global equivalent nodal mechanical load matrix, and $\{R\}_{T}$ is the global equivalent nodal temperature load matrix shown as Eq. (15).

$$
\begin{aligned}
& {[K]=\sum_{e}[k]^{e}=\sum_{e}\left(\iiint_{V^{e}}[B]^{e T}[D]^{e}[B]^{e} d x d y d z\right)} \\
& \{R\}_{T}=\sum_{e}\{R\}_{T}^{e}=\sum_{e}\left(\iiint_{V^{e}}[B]^{T}[D]\{\varepsilon\}_{T} d V\right)
\end{aligned}
$$

where $[k]^{e}$ is the element stiffness matrix, $[B]^{e}$ is the element strain matrix, $[D]^{e}$ is the element elastic matrix and $\{R\}_{T}^{e}$ is the matrix of equivalent nodal temperature load.

Boundary conditions which restrict the displacement of the global body are required. The nodal displacement can then be obtained by calculating Eq. (13). And the element strain $\{\varepsilon\}^{e}$ and stress $\{\sigma\}^{e}$ can be calculated from element nodal displacement using $\{u\}^{e}$ Eqs. (16) and (17), respectively.

$$
\begin{aligned}
& \{\varepsilon\}^{e}=[B]^{e}\{u\}^{e} \\
& \{\sigma\}^{e}=[D]^{e}[B]^{e}\{u\}^{\mathrm{e}}
\end{aligned}
$$

\subsection{Coupled thermal-mechanical analysis}

The governing equations of the coupled thermal-mechanical analysis of the spiral mandrel die are shown as Eq. (18) by combining Eqs. (6) and (13).

$\left\{\begin{array}{c}{\left[K_{T}\right]\{T\}=\{Q\}} \\ {[K]\{u\}=[F]+\{R\}_{T}}\end{array}\right.$

As there is little heat generated by plastic strain or friction in the spiral mandrel die assembly, the sequential one-way coupled thermal-mechanical analysis is conducted in this paper. It includes two steps. In the first step, the steady-state thermal analysis is fulfilled to determine temperature 
distribution and heat flow in the spiral mandrel die. The temperature load and pressure load on flow channel surfaces are then used as input for the following static structural analysis to calculate the stress, strain and deformation of the spiral mandrel die. Thus, the coupled thermal-mechanical problem is simplified, and the calculation time is greatly reduced with little influence on the calculation accuracy.

\subsection{Load mapping algorithm at fluid-solid interface}

The one-way coupling method is applied at the fluid-solid interface by assuming that the deformation of spiral mandrel die is quite small which has little effect on the flaw character of polymer melt. It means that only the temperature and pressure are transferred from polymer melts to the structure solver, while the deformation of the spiral mandrel die will not be transferred to the fluid solver. The heat resistance at fluidsolid interfaces are neglected in this case. The Smart Bucket Surface mapping algorithm is employed to map the temperature and pressure loads from polymer melts (mapping source) to the spiral mandrel die (mapping target) at the fluid solid interface. As the complete description of the algorithm has been presented by Jansen [24], a brief overview of it is presented in this section.

The Smart Bucket Surface mapping algorithm is conducted by dividing the source mesh at fluid-solid interface into an imaginary structured grid firstly. Each of the generated grid section is called a "bucket" as shown in Fig. 1a. Then, each node of the target mesh is associated with a bucket. On one hand, each of the associated target node in the bucket will be matched to a source element if the bucket is non-empty. One the other hand, if the bucket is found to be empty, the closest non-empty bucket is found and each target nod is mapped to one source element and mapping weights are calculated. The procedure to match the target node to one source element in the bucket is as follows.

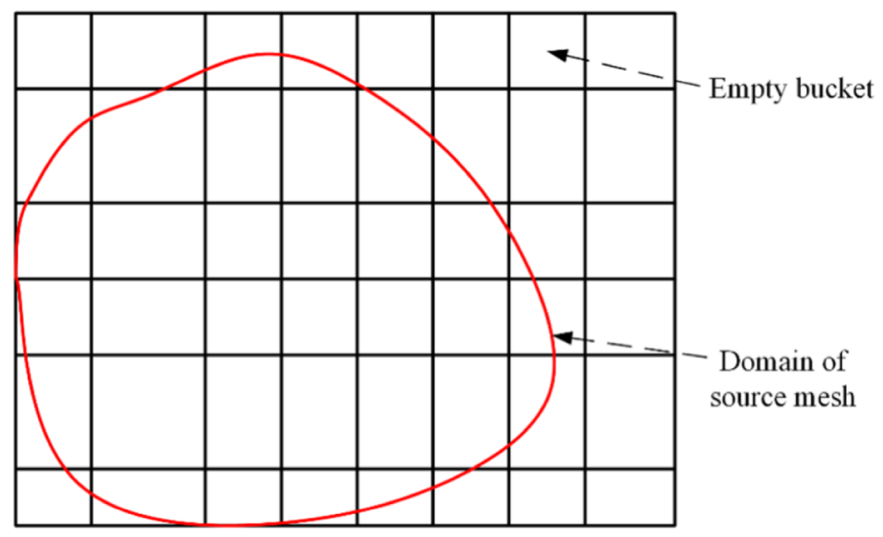

(a)
Firstly, all the source elements in the bucket are looped to check if the target node is within their domain. This is conducted by employing the vector of natural coordinates for each source element in the bucket. It is calculated by solving the set of equations given by the isoperimetric mapping below [24]:

$$
\{\widehat{x}\}=\left[\mathrm{N}_{a}^{e}(\xi)\right]\left\{x_{a}^{e}\right\}
$$

where $\{\widehat{x}\}$ is the vector of global coordinates of the target node, $N_{a}^{e}(\xi)$ is the matrix of linear shape functions associated with the source element, and $\left\{x_{a}^{e}\right\}$ is the vector of global coordinates of element-local node $a$. The following criteria are then applied to check if the target node is within the domain of the source element.

In the case of a quadrilateral source element, the target node is regarded as within the domain of the source element if the calculated natural coordinates $\xi$ satisfy the conditions in Eq. (20) below.

$\left\{\begin{array}{l}\left|v_{1}\right| \leq 1 \\ \left|v_{2}\right| \leq 1\end{array}\right.$

where $v_{1}$ and $v_{2}$ are the components of the natural coordinates $\xi$. While, if the natural coordinates $\xi$ satisfy the conditions in Eq. (21), the target node is regarded as in the domain of the source element within the specified tolerance tol, whose value is set as 0.05 in this research.

$$
\left\{\begin{array}{l}
1<\left|v_{1}\right| \leq 1+\text { tol } \\
1<\left|v_{2}\right| \leq 1+\text { tol }
\end{array}\right.
$$

Figure $1 \mathrm{~b}$ shows the concept in the case of a quadrilateral source element, where node B satisfies conditions in Eq. (20) and node A satisfies the conditions in Eq. (21).

In the case of a triangle source element, the conditions in Eqs. (22) and (23) are applied to check if the

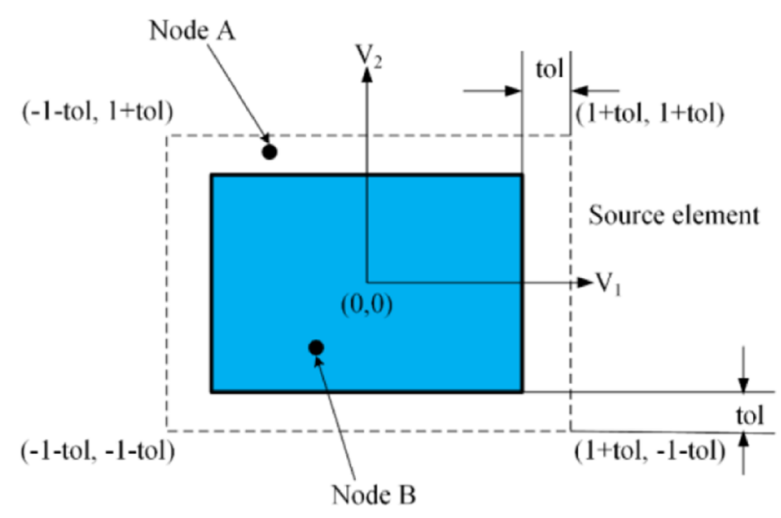

(b)

Fig. 1 a Overlaid the source mesh with buckets. b A quadrilateral source element with target nodes (node A: a target node that maps to the source element within the specified tolerance "tol," node B: a target node that exactly maps to the source element) [24] 
target node is within or without the domain of the source element, separately.

$$
\begin{gathered}
\left\{\begin{array}{c}
v_{1} \geq 0 \\
v_{2} \geq 0 \\
1-v_{1}-v_{2} \geq 0
\end{array}\right. \\
\left\{\begin{array}{c}
0>v_{1} \geq-t o l \\
0>v_{2} \geq- \text { tol } \\
0>1-v_{1}-v_{2} \geq- \text { tol }
\end{array}\right.
\end{gathered}
$$

It is possible that a target node is found within more than one domain of the source elements. To pair each target node with only one source element, the gap which is defined as the Euclidean distance from the target node projecting to a source element is calculated. Only the source element with identical and minimized gap is paired to the target node. The mapping weights are then determined by evaluating the finite element shape functions associated with the paired source element at the target node. If no target node-to-source element match is found in a non-empty bucket, the unmapped target nodes are still simply mapped to the nearest source node in the bucket, and the mapping weights are evaluated using the Bucket Surface algorithm.

\section{Finite element model}

\subsection{Geometry and material properties}

A typical spiral mandrel die for pipe extrusion provided by Ningbo Graewe-Fangli Extrusion Equipment Co., LTD. is shown in Fig. 2a. The engineering drawing of the die

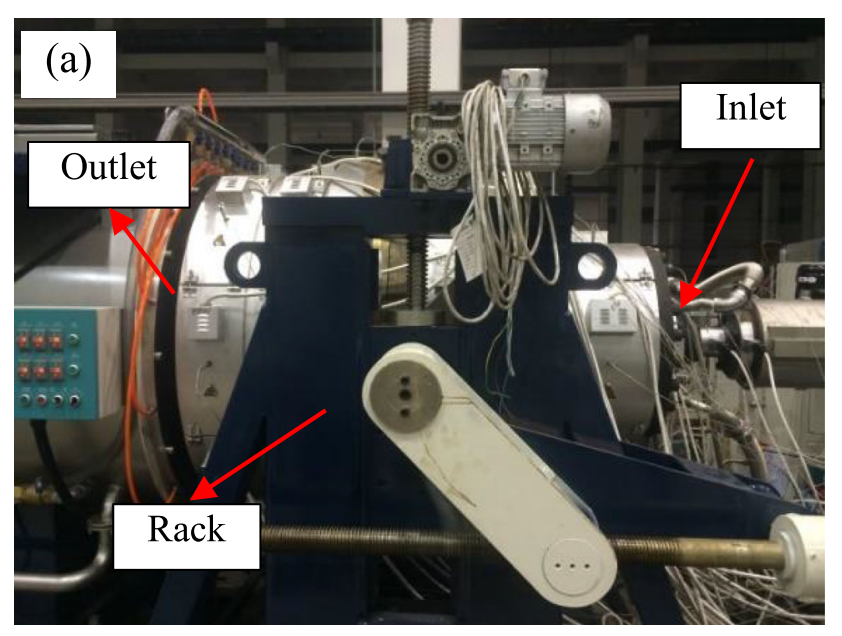

Fig. 2 Geometry of the spiral mandrel die for pipe extrusion: a actual spiral mandrel die to extrude the pipe with diameter of $1200 \mathrm{~mm}$ and $\mathbf{b}$ engineering drawing of the spiral mandrel die: (1) die plate, (2) die head, (3) die head transition part, (4) outer connection part, (5) die land support, (6) compression ring, (7) colour scaling ring group, (8) die land transition assembly is shown in Fig. 2b. It consists of the outer components such as die plate, die head and die land and the inner components such as diversion cone, spiral mandrel and die pin. The inner and outer die components are assembled together to generate the flow channel for the polymer melts to flow through. The spiral mandrel die is held at the die head transition part by a rack. There are ceramic and oil-bath heaters at the outer and inner surfaces, respectively, to control the die temperature in the extrusion process.

A slight simplification of the geometry of the spiral mandrel die is essential before generating a FE model. The bonded contacts between die parts are assumed, and the extrusion die is regarded as a whole part in this research. The assembly holes and chamfer surfaces are omitted to increase the calculation efficiency. As most of the geometrical features of the spiral mandrel die are maintained, the simplification will have little effect to the results of interests.

The simplified geometry is thus shown in Fig. 3. Figure 3a shows that the melt flow is divided into several streams at the die inlet. Both spiral flow and the axial leakage flow are generated around the spiral mandrel. The flow becomes annular at the outlet of the spiral grooves. The polymer melt will then flow through expansion, concentration and parallel channels before flowing out of the extrusion die. For ease of illustration, the die body is divided into three sections as shown in Fig. 3c, which are the inlet, spiral and forming sections. It can be seen from Fig. $3 b$ that the die geometry has a periodic nature which means that the calculation time can be reduced by simulating only one-sixth of the spiral mandrel die. As the structural parameters of spiral mandrel including initial depth of spiral groove $H$, end radius of mandrel $R_{3}$ (determines the taper angle of mandrel) and helix angle $\alpha$ have great influence on

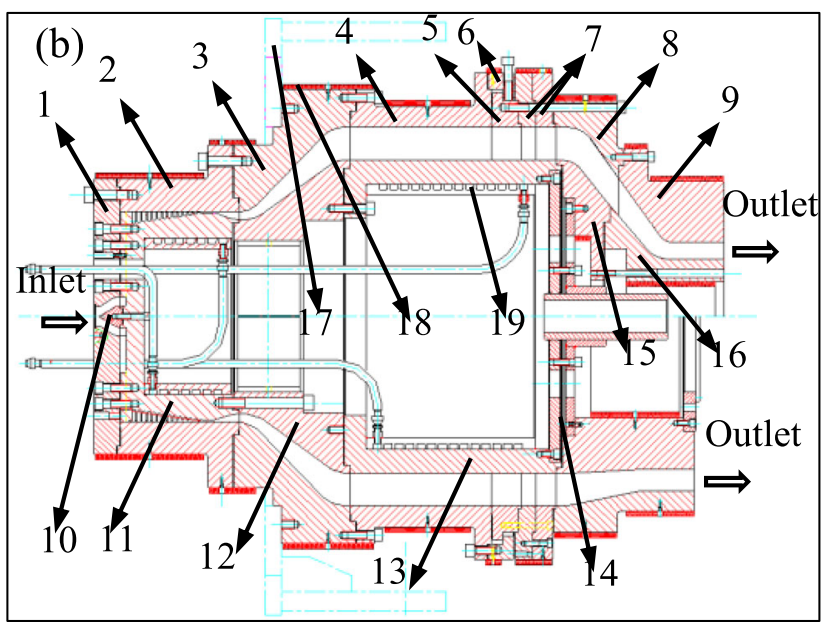

part, (9) die land, (10) diversion cone, (11) spiral mandrel, (12) inner transition part, (13) inner connection part, (14) connection plates, (15) die pin transition part, (16) die pin, (17) rack, (18) ceramic heaters and (19) oil-bath heaters 


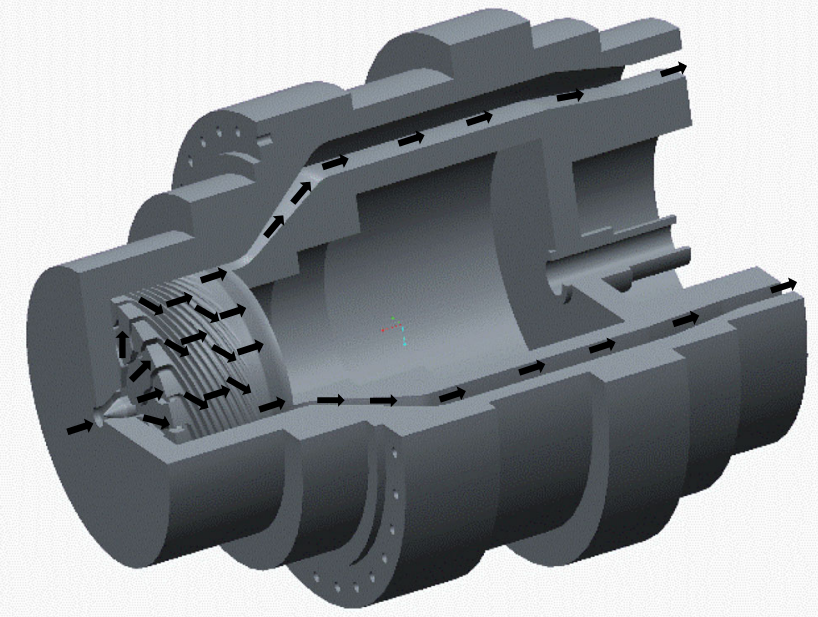

(a)

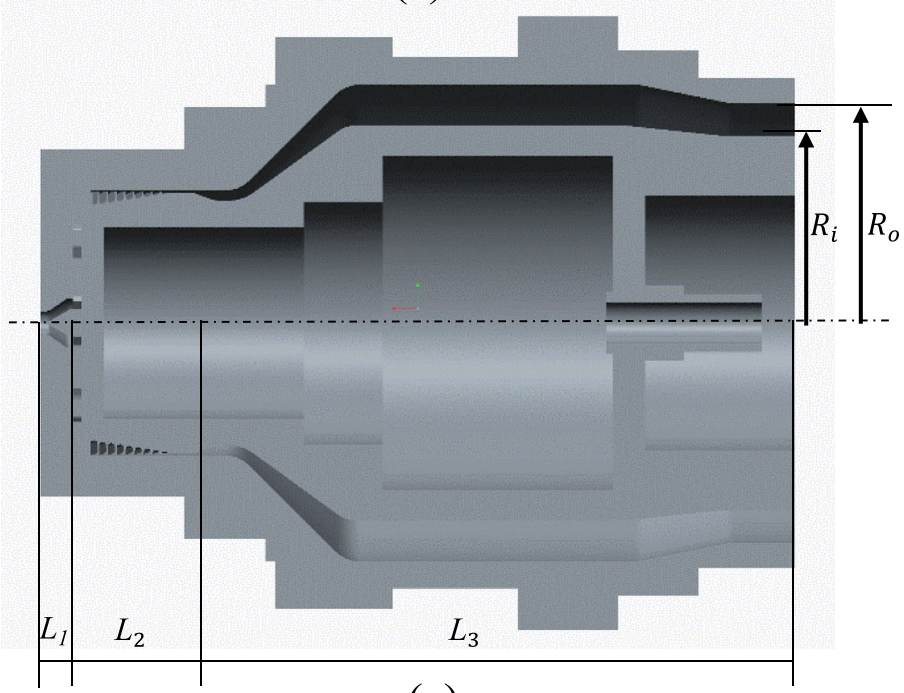

(c)

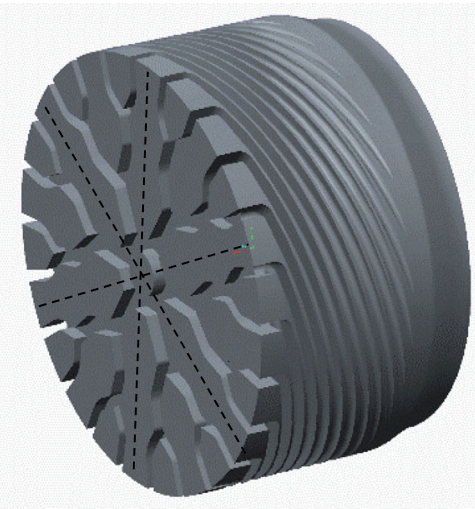

(b)

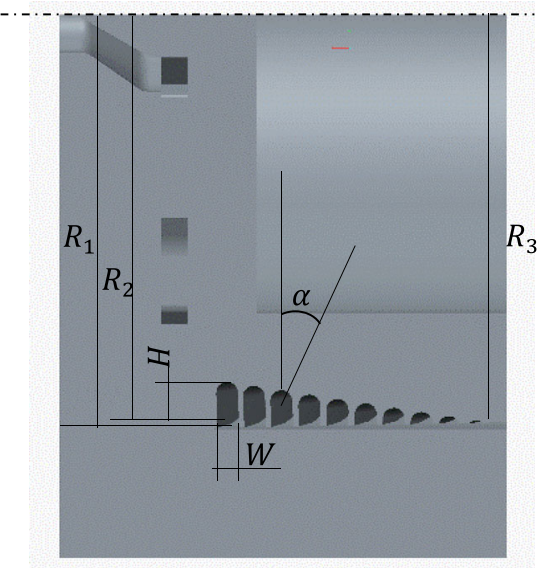

(d)

Fig. 3 Geometric model of the spiral mandrel die: a cut away isometric view, $\mathbf{b}$ geometry of the spiral mandrel, $\mathbf{c}$ cross-sectional view, and $\mathbf{d}$ detailed view of the spiral section

both the flow behaviour of polymer melt and the mechanical properties of the die body, they are marked as shown in Fig. $3 \mathrm{~d}$ and will be studied in section 5 . The essential structural parameters of the die body are shown in Table 1 . The material used for the spiral mandrel die is the $40 \mathrm{Gr}$ structural steel, whose thermal and mechanical properties are shown in Table 2.

\subsection{Finite element mesh and boundary conditions}

The coupled thermal-structural modelling was performed using the commercially available finite element package, ANSYS. Considering the spiral mandrel die is cyclic symmetry for each $60^{\circ}$, one-sixth of the geometry is considered to reduce the computational calculation time. The FE model is generated using the 10-node quadratic tetrahedral elements (ANSYS solid 187), 13-node quadratic pyramid elements
Table 1 Essential geometric parameters of the spiral mandrel die

\begin{tabular}{ll}
\hline Geometric parameters & Values $(\mathrm{mm})$ \\
\hline Length of the inlet section $(L 1)$ & 120 \\
Length of the spiral section $(L 2)$ & 330 \\
Length of the forming section $(L 3)$ & 1800 \\
Outer radius of flow channel outlet $\left(R_{o}\right)$ & 645 \\
Inner radius of flow channel outlet $\left(R_{i}\right)$ & 550 \\
Number of spiral channels & 24 \\
Helix angle $(\alpha)$ & $14.357^{\circ}$ \\
Width of initial spiral groove $(W)$ & 20 \\
Initial depth of spiral groove $(H)$ & 48 \\
Inner radius of die head $\left(R_{1}\right)$ & 389 \\
Initial radius of mandrel $\left(R_{2}\right)$ & 388 \\
End radius of mandrel $\left(R_{3}\right)$ & 382 \\
\hline
\end{tabular}


Table 2 Material property parameters of $40 \mathrm{Gr}$ structural steel

\begin{tabular}{ll}
\hline Parameters & Values \\
\hline Density $\left(\mathrm{kg} / \mathrm{m}^{3}\right)$ & 7850 \\
Thermal conductivity $\left(\mathrm{W} / \mathrm{m}^{\circ} \mathrm{C}\right)$ & 60.5 \\
Coefficient of thermal expansion & $1.2 \mathrm{e}-5$ \\
Young's modulus $(\mathrm{Pa})$ & $2 \mathrm{e} 11$ \\
Poisson's ratio & 0.3 \\
Tensile yield strength $(\mathrm{Pa})$ & $\geq 7.85 \mathrm{e} 8$ \\
Compressive yield strength $(\mathrm{Pa})$ & $\geq 9.8 \mathrm{e} 8$ \\
\hline
\end{tabular}

(ANSYS solid 186) and the 20-node quadratic hexahedral element (ANSYS solid186), as shown in Fig. 4a. The mesh around the spiral grooves is refined as shown in Fig. $4 \mathrm{~b}$. 840,926 Eight hundred forty thousand nine hundred twentysix elements and 1,326,479 nodes are generated in total. The meshes on the symmetrical surfaces are maintained to match each other. To make the load mapping at fluid-solid interface efficient, the mesh topology at the surface of flow channel is set the same as that in the previous fluid modelling of polymer melt flow.

For the steady-state thermal analysis, the heated inner surfaces of the spiral mandrel die are set as $200{ }^{\circ} \mathrm{C}$ and the heated outer surfaces are set as $220^{\circ} \mathrm{C}$, respectively. The convection is taken into account between the free surfaces of the die and the surrounding air. The environment temperature is set as $22{ }^{\circ} \mathrm{C}$, and the convection coefficient is set as $6 \mathrm{~W} / \mathrm{m}^{2}{ }^{\circ} \mathrm{C}$. The temperature on the flow channel of the die is mapped from previous simulation of polymer melts flow using the Smart Bucket Surface algorithm. Figure 5a shows the maximum temperature of cross section at several positions along the extrusion direction [21]. It demonstrates that the temperature on the flow channel increases gradually from die inlet to outlet due to the viscous dissipation in the polymer melts. For the static structural analysis, the mesh used is the same as that for the above thermal analysis. The displacements at the supporting points (assembly holes) of the spiral mandrel die is constrained in $x, y$ and $z$ directions. The loads on the die consist of both the thermal and pressure loads. The thermal load is mapped from temperature distribution calculated from the above thermal analysis. The pressure load on the flow channel is mapped from the previous simulation of polymer melts flow. Figure $5 \mathrm{~b}$ shows the maximum pressure of cross section at several positions along the extrusion direction [21]. The maximum pressure is found at the inlet of the flow channel. Both the mapped thermal load on die body and pressure load on flow channel will lead to the stress, strain and deformation of the spiral mandrel die.

\section{Results and validation}

\subsection{Modelling results}

The thermal analysis is carried out by calculating all the nodal thermal values dependent on the thermal resistance of the materials. The calculated temperature distribution of the spiral mandrel die is shown in Fig. 6, which demonstrates that the temperature reduces gradually from die outer surface to inner surface (Fig. 6a). The temperature gradient of the extrusion die will lead to thermal stress in the die body. The maximum and minimum temperatures happen at the outer and inner surfaces (Fig. 6b), respectively. The calculated temperature distribution will then be used as thermal load on the complete die body to calculate the stress and strain responses.

Figure $7 \mathrm{a}$ and $\mathrm{b}$ show the deformation induced by thermal load and pressure load at periodic surface of the spiral mandrel

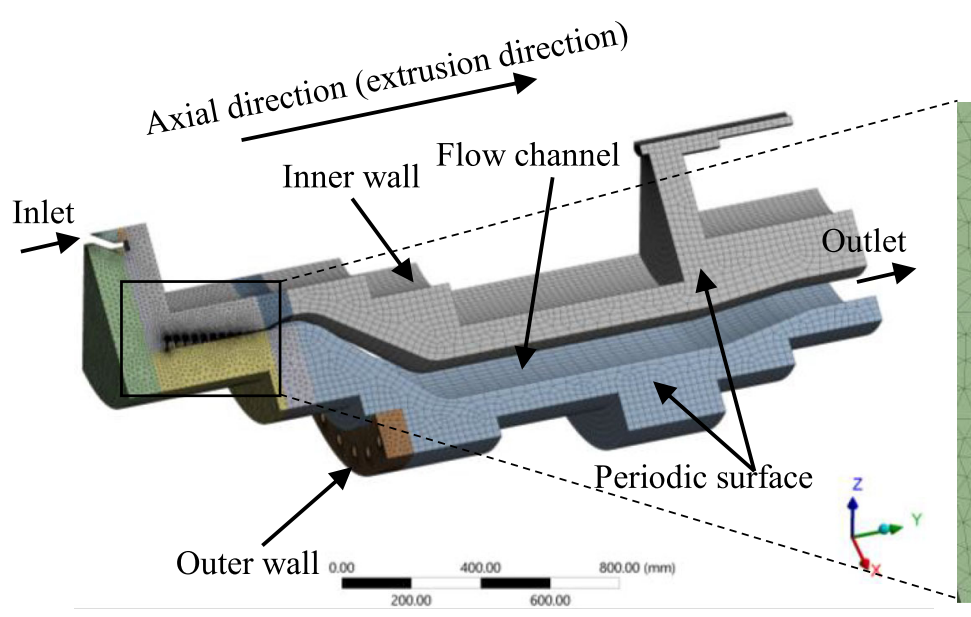

(a)

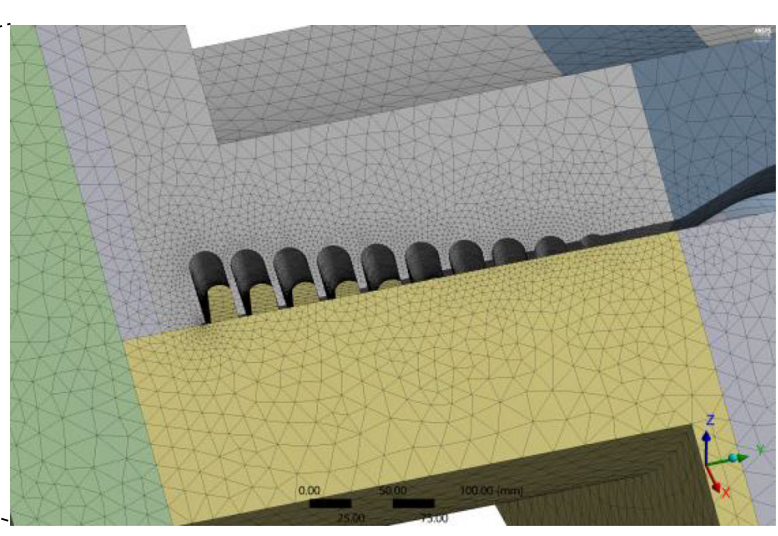

(b)

Fig. 4 a Isometric view (origin is defined at the centre of the round inlet) and $\mathbf{b}$ detailed view at the spiral sections of finite element model 

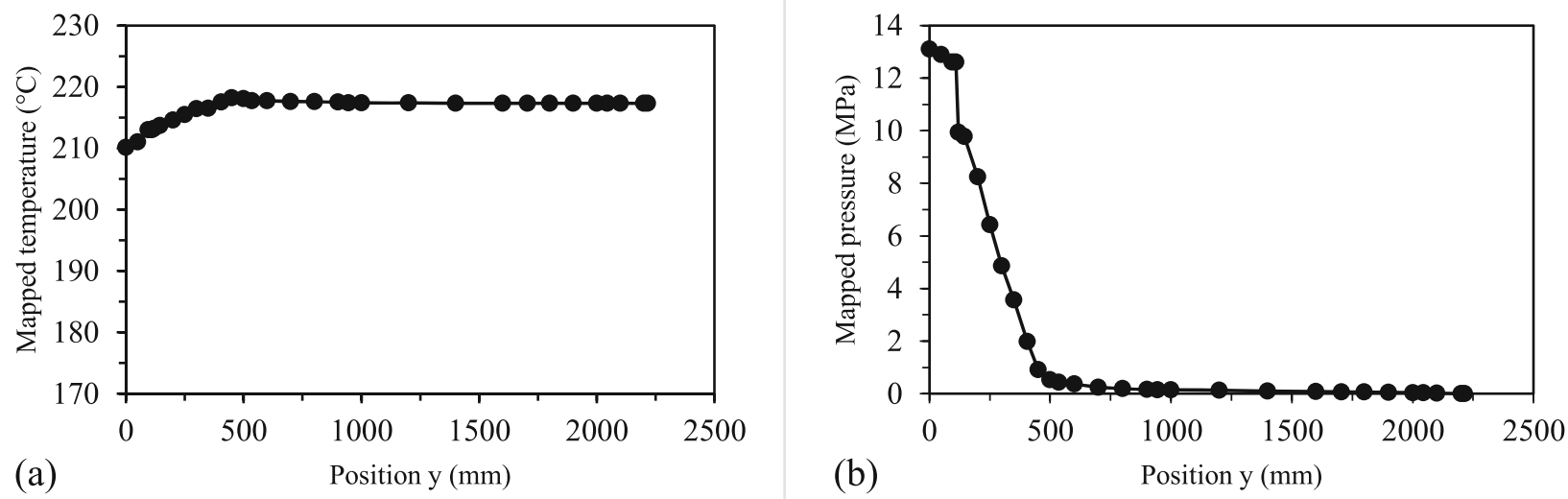

Fig. 5 Variation of mapped a temperature load and $\mathbf{b}$ pressure load on the flow channel along extrusion direction for thermal analysis and structural analysis, respectively

die, separately. The maximum deformation induced by thermal expansion of the die body is found at the die orifice with a deformation of $5.94 \mathrm{~mm}$. Such large deformation can lead to the increase of both diameters and thickness of the annular extrudate or result in the fracture of the ceramic heater equipped at the outer surface of the die body. It is thus suggested that the ceramic heaters are connected using spring joints in the circumference which allows the heaters to expand with the thermal expansion of the die body. Though it is found that the deformation of the spiral mandrel die is generated mainly by the thermal load, the pressure induced deformation should also be regarded. The maximum deformation of $0.132 \mathrm{~mm}$ induced by the pressure load is found near the inlet of the spiral grooves, which shows that the gaps between each spiral groove should be strong enough to resist the pressure when designing the die mandrel.

The total deformation at flow channel on periodic surface for both outer and inner walls is shown in Fig. 7c. The variation of total, radial and axial deformations at the flow channel along extrusion direction ( $y$-axis) is correspondingly plotted in Fig. 8. The axial deformations are found to linearly increase along the extrusion direction, while the radial deformations hold the change pattern consistent with the shape of the flow channel. Due to the difference of radial deformations for outer wall and inner wall at the die orifice, the thickness of the annular extrudate will be increased by $0.303 \mathrm{~mm}$ due to deformation of the die body.

The coupled thermal-mechanical stress of the die body is shown in Fig. 9. The stress in the die body in the forming section is found to be less than $61.84 \mathrm{MPa}$, which is far smaller than the yield stress of $785 \mathrm{MPa}$ for the die material (40Gr structural steel). It is thus suggested that the material of the die body in forming section could be replaced by a cheaper steel such as cast iron ZG 270-250 in Chinese standard, whose yield stress is $270 \mathrm{MPa}$. In addition, stress concentration is found at the inlet of the spiral grooves. The maximum stress calculated is $640.2 \mathrm{MPa}$ which is near the yield stress of the die material $40 \mathrm{Gr}$ structural steel. The stress concentration will easily lead to the plastic deformation of the mandrel, and cracks will possibly initiate and grow here under cyclic thermal and pressure loads.

It is known that the temperature induced deformation can be calculated and predicted easily by multiplying corresponding dimension with thermal expansion coefficient

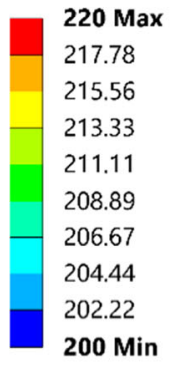

${ }^{\circ} \mathrm{C}$

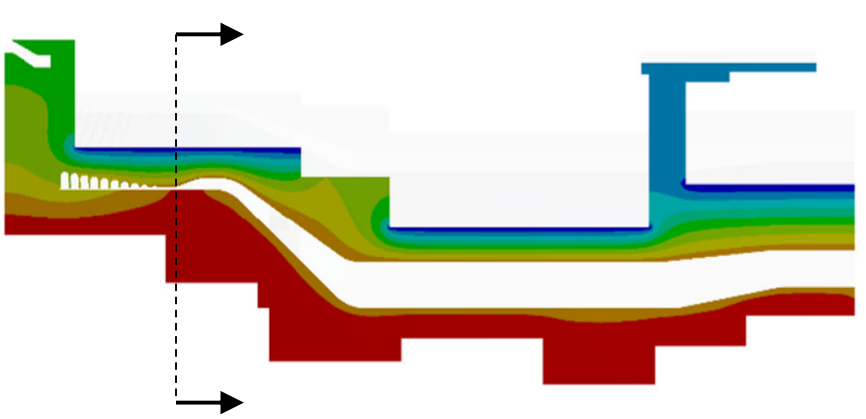

(a)

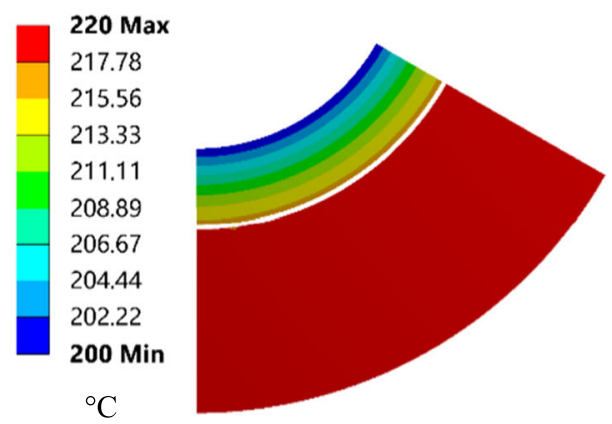

(b)

Fig. 6 Calculated temperature distribution on die body: a periodic surface and $\mathbf{b}$ cross section $(y=330 \mathrm{~mm})$ vertical to axial direction 
(a)

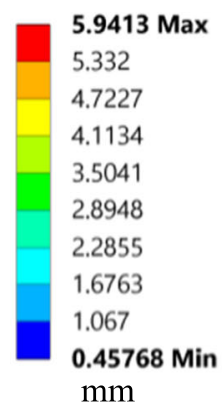

(b)

0.13206 Max

0.1174

0.10274

0.088076

0.073413

0.05875

0.044087

0.029424

0.014761

9.8286e-5 Min

$\mathrm{mm}$

(c)
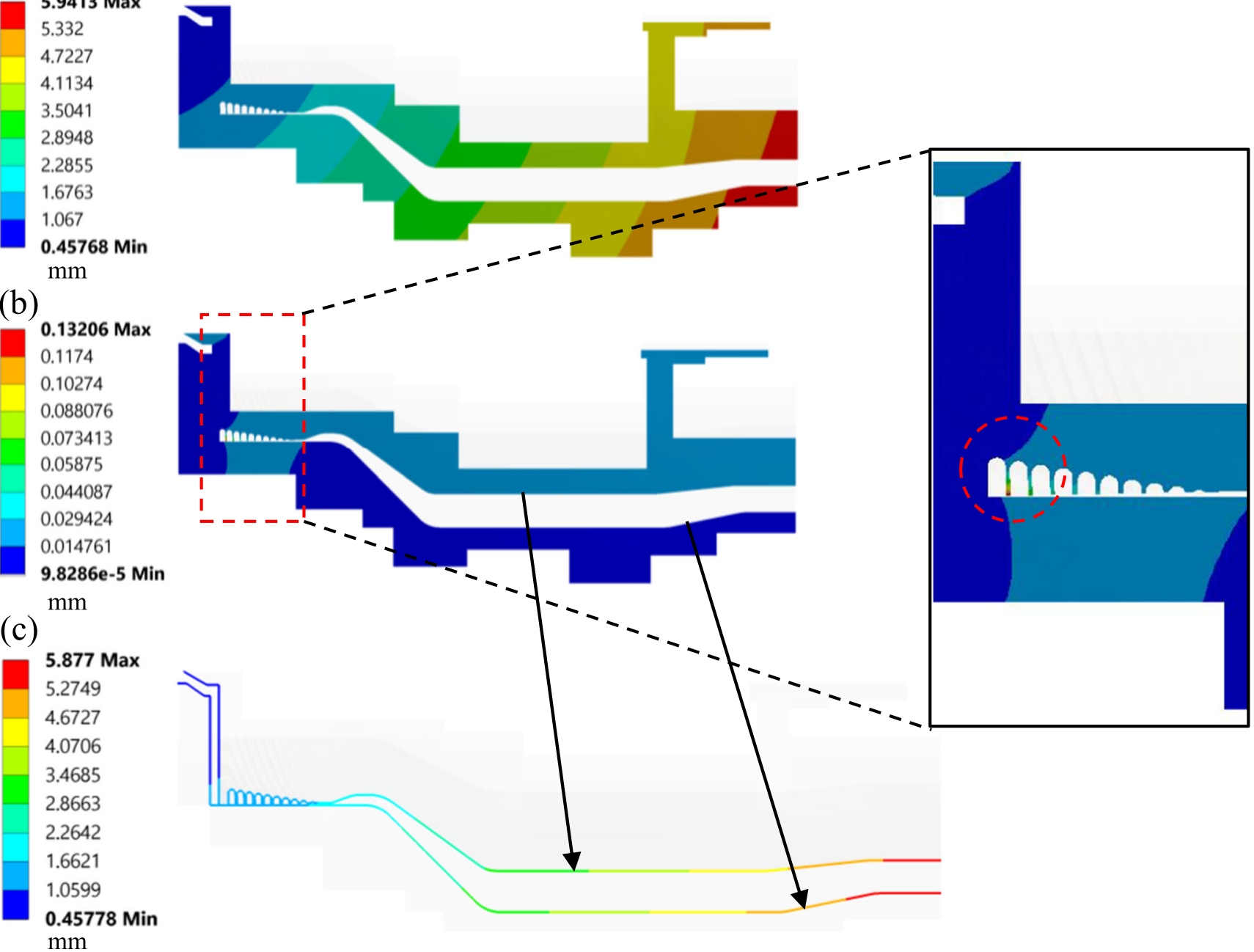

Fig. 7 Deformation distribution at periodic surface of the spiral mandrel die: a temperature-induced deformation, $\mathbf{b}$ pressure-induced deformation and $\mathbf{c}$ total deformation at flow channel

of material and temperature change. However, the pressured induced deformation is normally hidden due to the complicated flow of polymer in the flow channel of spiral mandrel die. It is required by Hopmann and Michaeli [4] that the pressure induced maximum deformation at the die orifice should remain less than $0.05 \mathrm{~mm}$. In this case, it is calculated as $0.0245 \mathrm{~mm}$, which indicates that the current design of the spiral mandrel die is conservative. In addition, the maximum coupled thermalmechanical stress should be regarded since plastic deformation or cracking will happen when the maximum stress exceeds the yield stress of the die material. The calculated maximum stress is $640.2 \mathrm{MPa}$ in this case. The effect of the structural parameters and processing parameters on the maximum pressure-induced deformation at the die orifice and coupled thermal-mechanical stress will be analysed in the following section.

\subsection{Experimental validation}

As shown in Fig. 10a, the temperature, deformation and strain (stress) at 3 pairs of points on surface of the spiral mandrel die were measured in the experiment. The first pair (A1 and A2) located on the surface of die land. The second pair (B1 and B2) was at colour scale ring group. The third pair ( $\mathrm{C} 1$ and $\mathrm{C} 2)$ was set at the surface of head transit. The measurement points of each pair were located at the same cross section vertical to the extrusion direction, and they had an angle of $90^{\circ}$. Thermocouples, dial indicators and strain gages were applied to measure the temperatures, deformations and strains at each measurement point, as shown in Fig. 10b, c. The thermocouples were stuck on the surface of the extrusion die by polyimide tape, which could tolerate the temperature range of $0-300{ }^{\circ} \mathrm{C}$ long term. Digital thermometers were used to receive the electrical signals produced by thermocouples 
Fig. 8 Variation of total, radial and axial deformations of flow channel on periodic surface of both outer wall $(\mathrm{OW})$ and inner wall (IW) along extrusion direction (or $y$-axis)

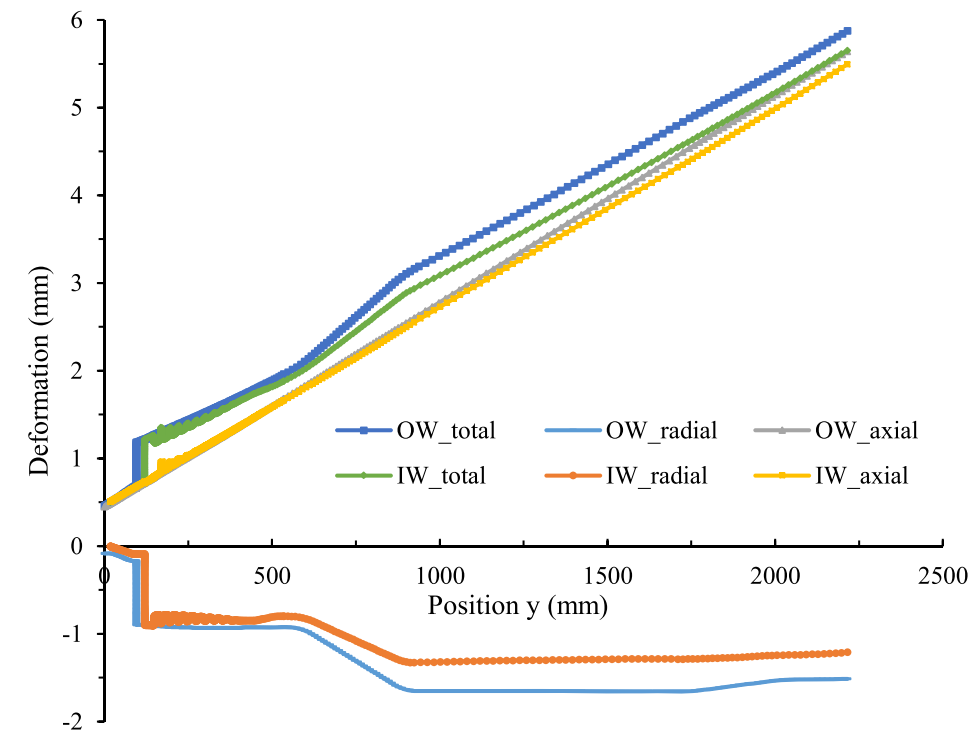

and indicate the measured temperatures. The deformations in extrusion direction could be measured directly from the dial indicators, which were installed on the magnetic bases. All the magnetic bases were installed on the rack, which can be regarded as static.
The strain gages were welded parallel with the extrusion direction on the die surface using a spot welding machine to measure the strain (stress) in the extrusion (y-axis) direction. A strain measuring instrument together with a PC was used to record the measured strains. The quarter bridge circuit shown

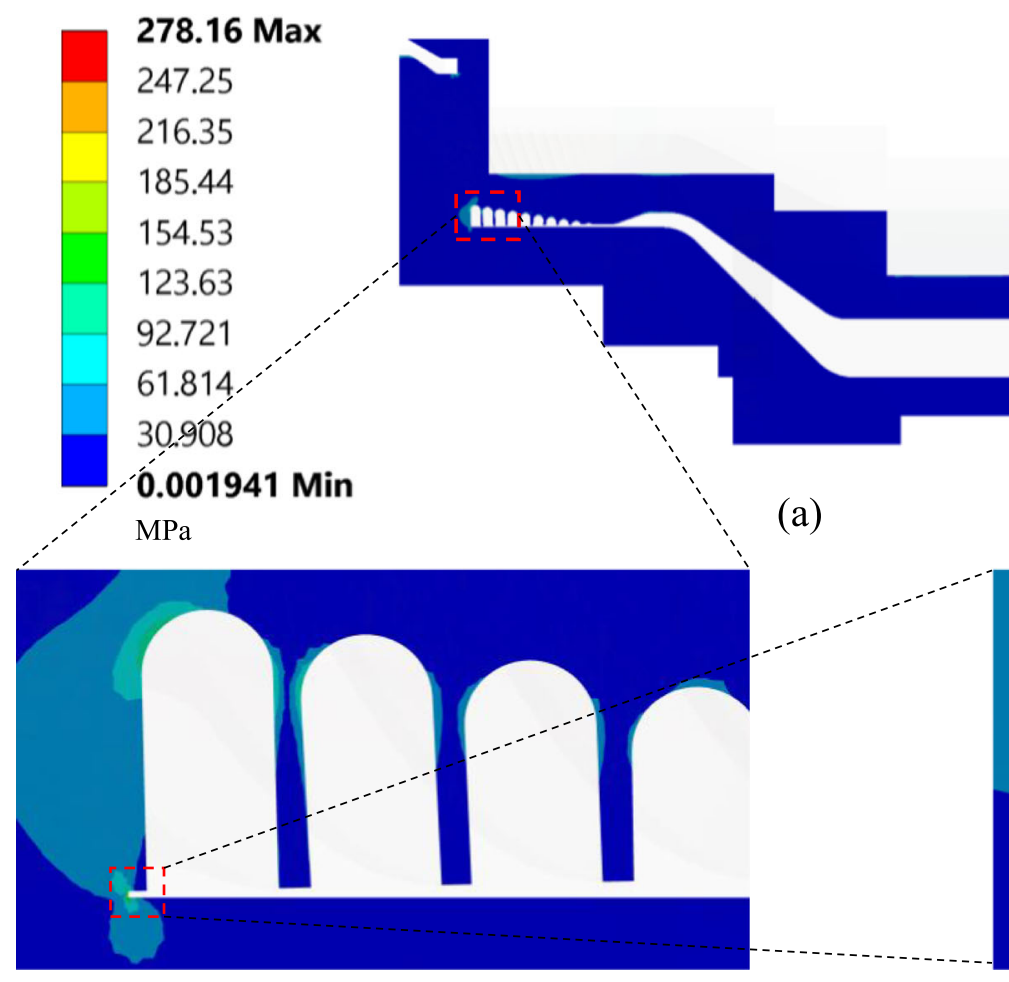

(b)

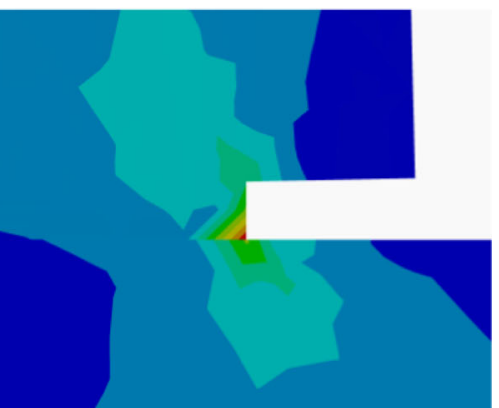

(c)

Fig. 9 Stress distribution at periodic surface of the spiral mandrel die: a equivalent von Mises stress, $\mathbf{b}$ enlarged view near inlet of spiral channel and $\mathbf{c}$ stress concentration at the inlet of spiral channel 

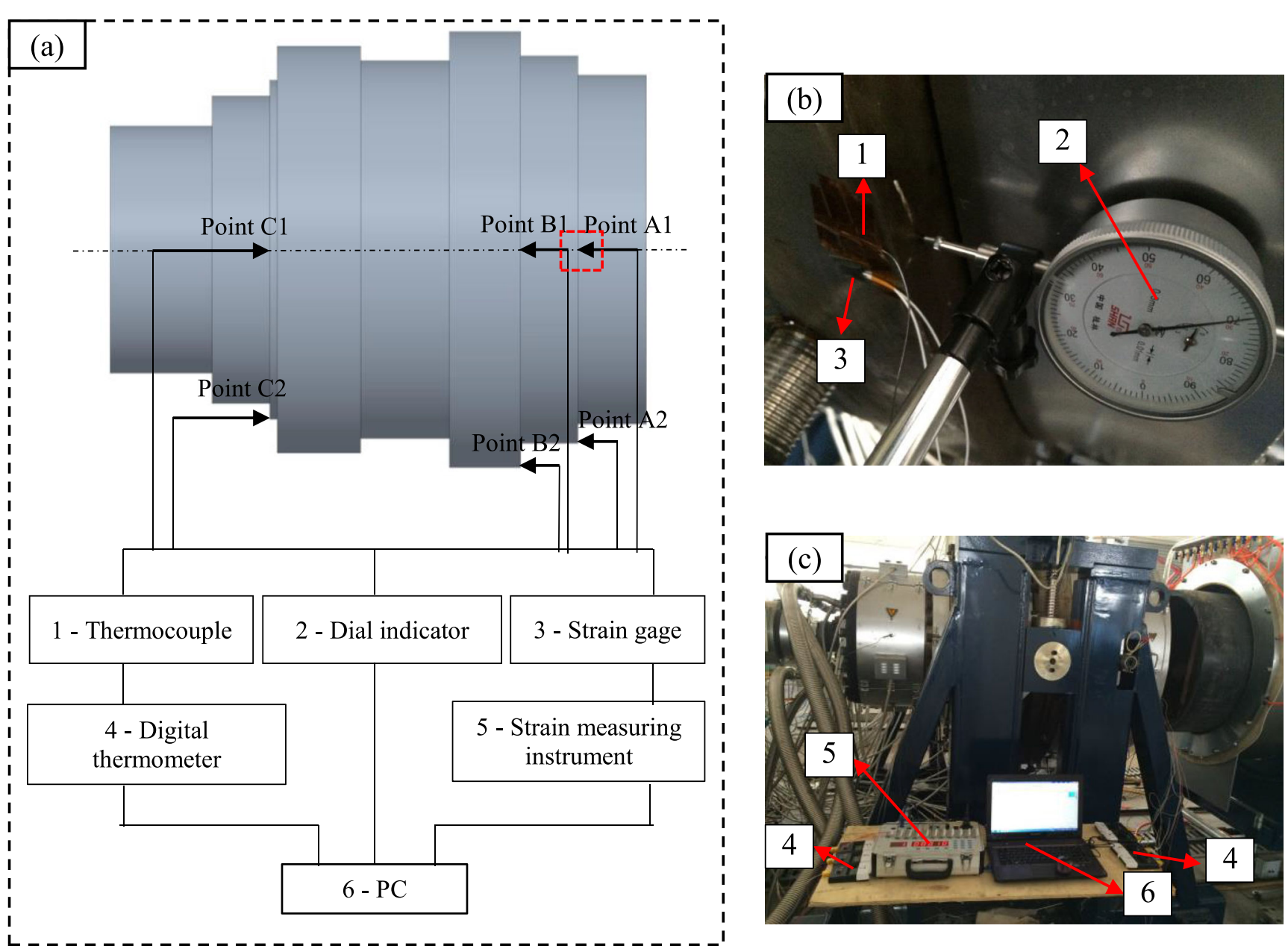

Fig. 10 Experimental system for measuring temperature, deformation and stress at outer surface of the spiral mandrel die: a schematic diagram, b sensors equipped at measure point $\mathrm{A} 1$ and $\mathbf{c}$ data acquisition unit

in Fig. 11a was chosen for the strain measurement, which can easily be configured and widely used for general stress/strain measurement. The output voltage due to stain of stain gauge $e \approx \frac{1}{4} \times K \times \varepsilon \times E$ $\operatorname{Rg}$ is as follows:

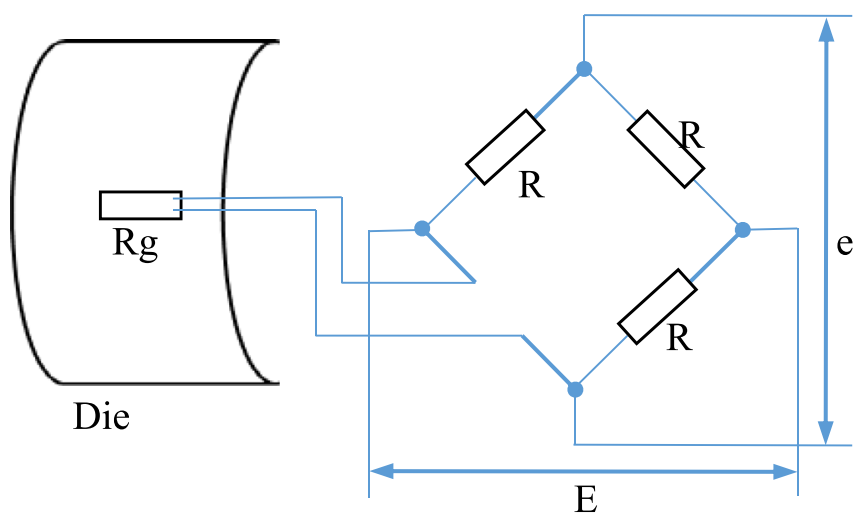

(a)

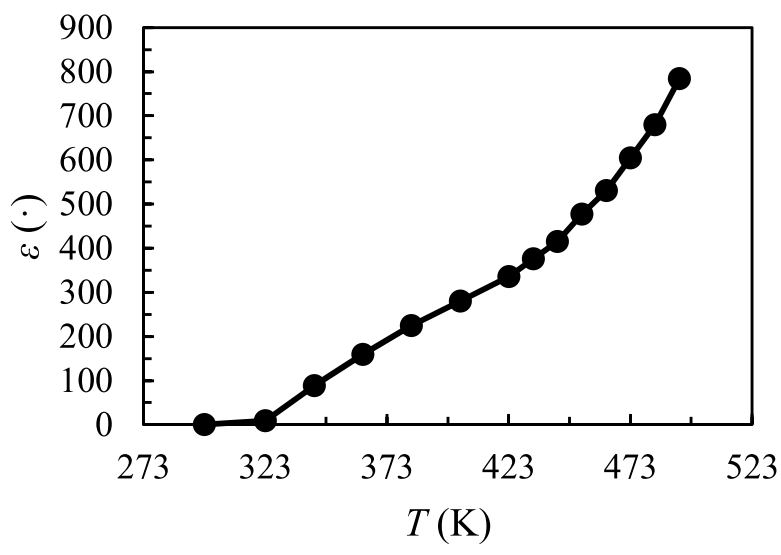

(b)

Fig. 11 a The quarter bridge circuit for the strain measurement of the spiral mandrel die. b Thermal output of the strain gauge versus different temperature 
where $e$ is the output voltage, $E$ is the bridge voltage, $K$ is the sensitivity coefficient of stain gauge and $\varepsilon$ is the measured strain along the extrusion direction.

But further modification of the measured strain is required in order to obtain the real initiated strain (the coupled thermalstructural strains) in the spiral mandrel die considering the lead wire resistance, thermal output and gauge factor at the working temperature [25]. Specially, the thermal output of the strain gauge is measured by welding it on a part with same material of the extrusion die under different temperature in a Muffle stove. The variation of the thermal output of the applied strain gauge versus different temperature is recorded as shown in Fig. 11b.

The experimental procedure is as follows:

1. The extrusion die was preheated before the extrusion process with ceramic heaters on outer surface of the extrusion die being set at around $220{ }^{\circ} \mathrm{C}$, and the ones on the inner surface of the extrusion die set at around $200{ }^{\circ} \mathrm{C}$. The temperatures of the

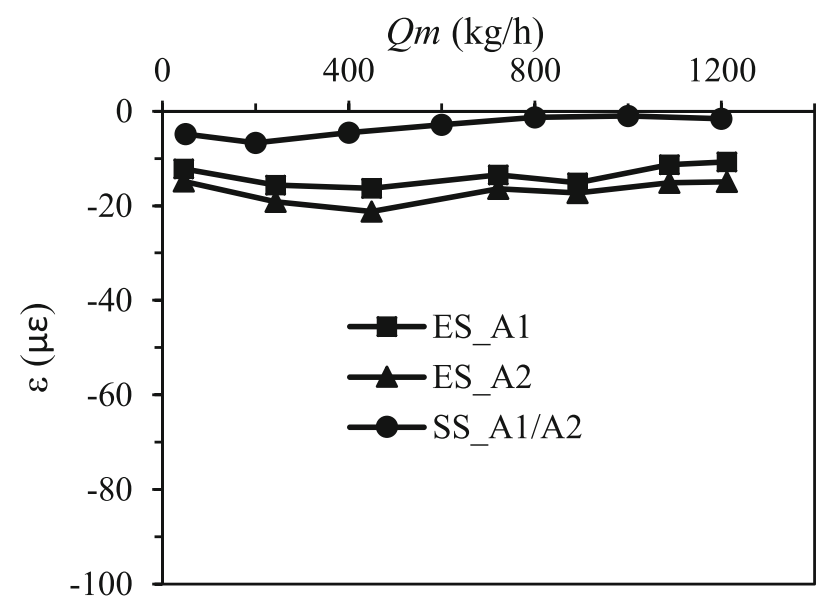

ceramic heaters were maintained unchanged in the extrusion process.

2. The dial indicators were set as zero in order to eliminate the deformation due to thermal expansion and prepare to measure the pressure induced deformation in the following extrusion process.

3. The temperature of the polymer melt was preheated to be $210^{\circ} \mathrm{C}$ in the extruder. The extruder was accurately controlled to extrude the HDPE at certain flow rate.

4. When a successive and stable extrusion process was achieved, the deformations at the 6 testing points were recorded 3 times, and the strain and temperature were recorded 5 times in a 15 -min period.

5. The melt temperature of resin was maintained at $210{ }^{\circ} \mathrm{C}$. Steps 3 and 4 were repeated under different flow rates. The temperature, deformation and strain at the 6 testing points at different flow rates were measured and recorded again.

The measured temperatures at all the 6 points were found to maintain at around $220{ }^{\circ} \mathrm{C}$ under different mass flow rates,

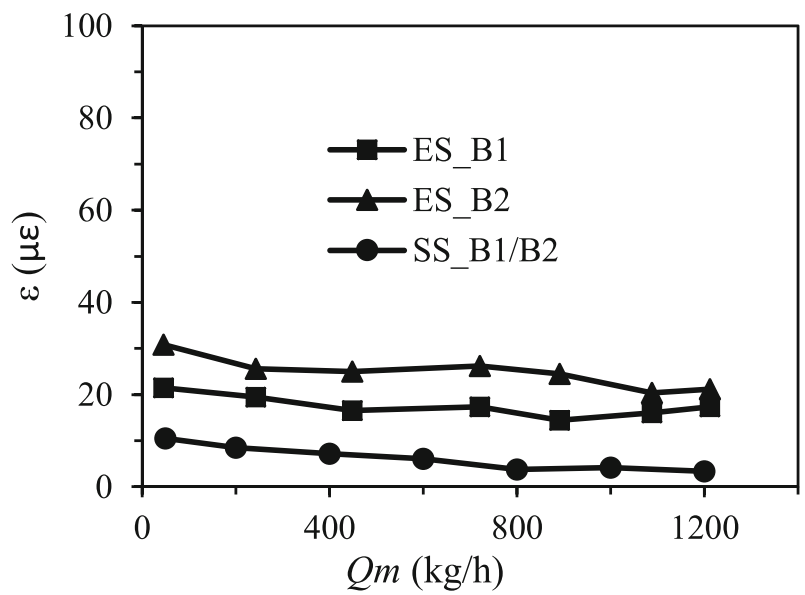

(b)

(a)

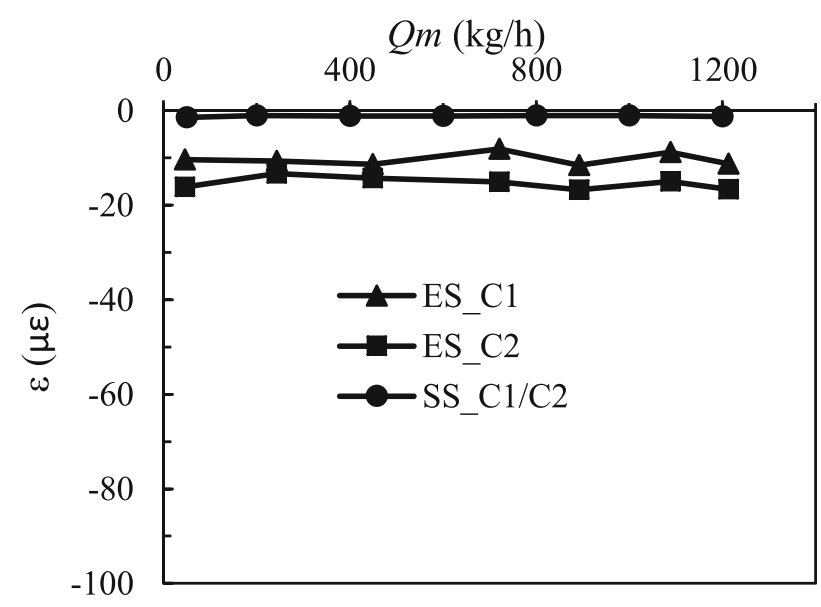

(c)

Fig. 12 Variations of coupled thermal-structural strain in axial direction ( $y$-axis) at the measurement points versus mass flow rate (ES experimental strain, SS simulated strain) 
which is consistent with the simulated results. The results are reasonable as the temperature on the outer surfaces of the spiral mandrel die is controlled and set as $220{ }^{\circ} \mathrm{C}$ by the ceramic heater during the extrusion process. The deformations at the 6 measurement points are found to be too small to be captured by the dial indicators, which will not be shown here therefore.

Figure 12 shows the measured strain in axial direction ( $y$ axis) at the 6 measurement points under different mass flow rates. The positive value means a tensile strain (stress) at the measurement point. It shows that there is also little variation in strain at the 6 measurement points, which indicates that the polymer melt has little influence on the stress rate on the outer surfaces of the spiral mandrel die. The generated thermal dissipation and pressure due to increase of mass flow rate will mainly lead to the increase of stress at the surfaces of the flow
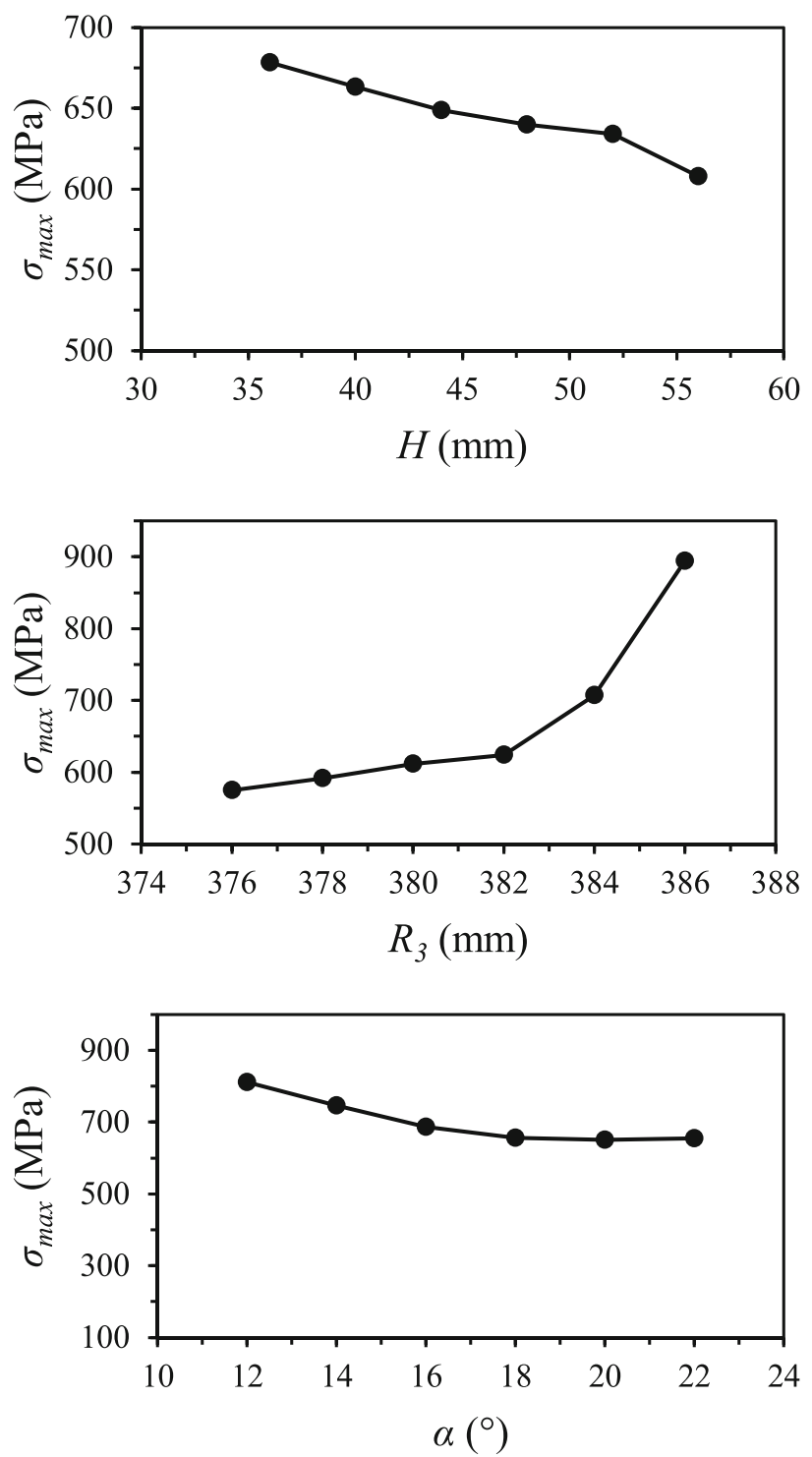

channel instead. It is also found that the absolute strains at points $\mathrm{A} 1, \mathrm{~B} 1$ and $\mathrm{C} 1$ are smaller than those at points $\mathrm{A} 2$, $\mathrm{B} 2$ and $\mathrm{C} 2$, respectively. It demonstrates that the generated pressure and thermal dissipation on flow channel are actually not symmetrical around the circumference. The result that the absolute values of simulated strains at the 6 measurement points are smaller than the experimental ones is also due to the fact that only the shear viscosity of the polymer melt is considered in the previous fluid simulation [21].

\section{Analysis and discussion}

The mandrel geometry has great influence on the flow pattern of polymer melts in the flow channel as observed in the previous study [21]. It is known that the mandrel geometry can be
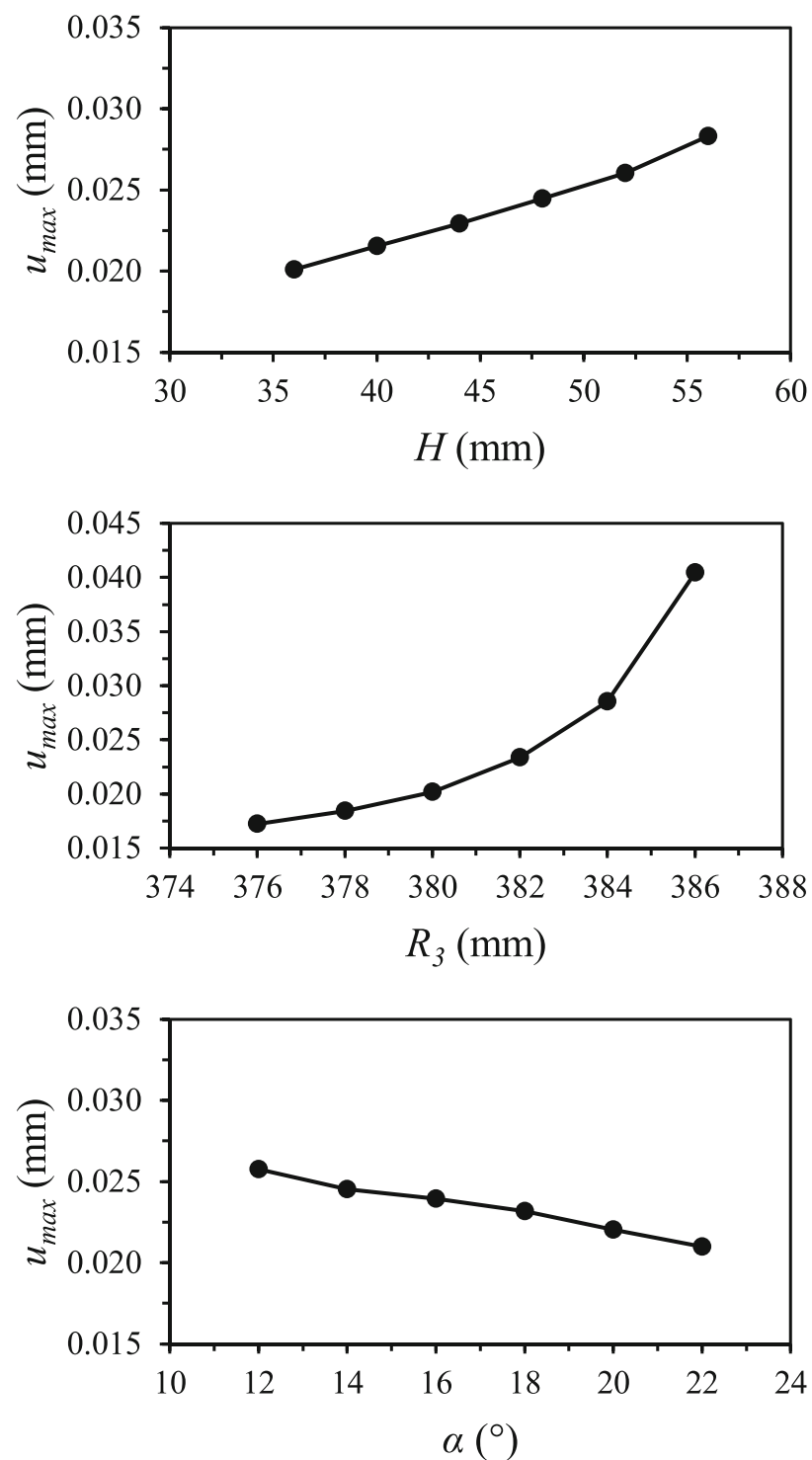

Fig. 13 Variation of maximum coupled thermal-mechanical stress $\left(\sigma_{\max }\right)$ in die body and maximum pressure induced deformation $\left(u_{\max }\right)$ at die orifice versus different mandrel parameters ( $H$ : initial depth of spiral groove; $R_{3}$ : end radius of mandrel; $\alpha$ : helix angle) 

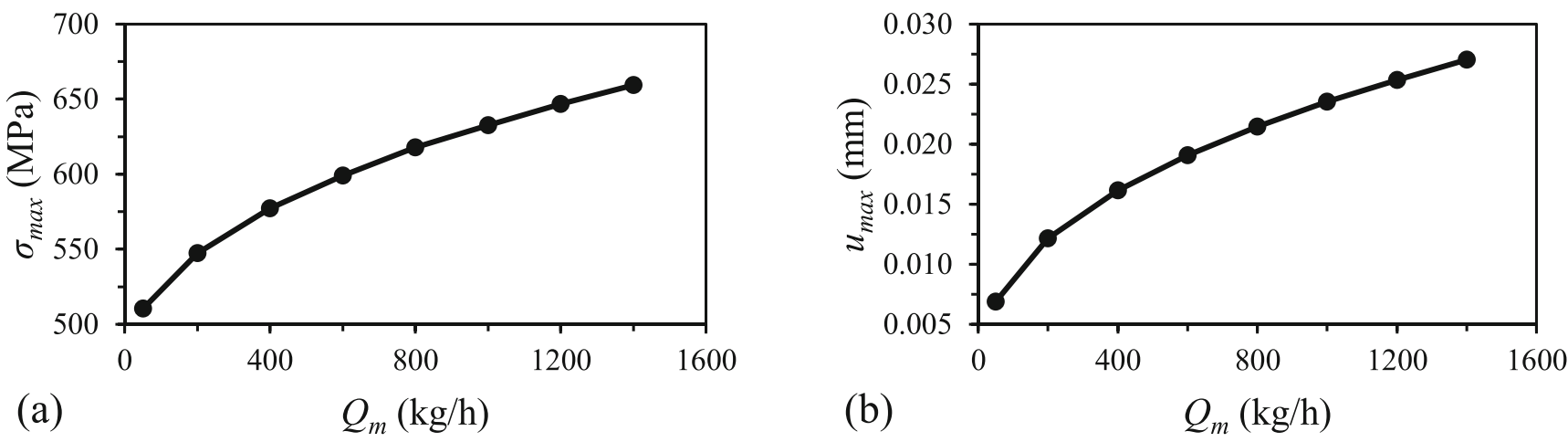

Fig. 14 Variation of a maximum coupled thermal-mechanical stress $\left(\sigma_{\max }\right)$ in die body and $\mathbf{b}$ maximum pressure induced deformation $\left(u_{\max }\right)$ at die orifice versus different mass flow rate $\left(Q_{m}\right)$

mainly determined by the parameters of initial depth of the spiral groove $(H)$, end radius of the mandrel $\left(R_{3}\right)$ and helix angle $(\alpha)$. The effects of the above three parameters on the die strength are evaluated as well in this section.

From the results shown in Fig. 13, it is clear that the coupled thermal-mechanical stress in the die body decreases as the initial depth of spiral groove $(H)$ increases. However, it can result in the increase of the pressure induced deformation at the die orifice. In addition, the end radius of the mandrel $\left(R_{3}\right)$ exerts a strong effect on the strength and stiffness of the die body. When the end radius of the mandrel increases, higher maximum stress and deformation can be obtained. It is also found that the maximum stress decreases as the helix angle increases from $12^{\circ}$ to $16^{\circ}$. When the helix angle continues to increase, the maximum stress stays almost unchanged at about $650 \mathrm{MPa}$. The maximum deformation at the die orifice decreases slightly with the increase of the helix angle.

It is known from previous study that the pressure drop of flow channel varies greatly with different flow rates at inlet [21]. The effect of mass flow rate $\left(Q_{m}\right)$ on the mechanical properties of the die body is thereby studied, shown in Fig. 14. It demonstrates that the mass flow rate exerts great influence on the stress and deformation of the die body. Both the maximum stress in die body (Fig. 14a) and maximum deformation at die orifice (Fig. 14b) increase with the increase of mass flow rate. Though the higher mass flow rate means increased productivity, it is necessary to determine a suitable mass flow rate to avoid unacceptably high stress and deformation of die body.

\section{Conclusions}

The paper presents a coupled thermal-structural modelling framework incorporating finite element method and Smart Bucket Surface mapping algorithm for evaluating mechanical properties of a spiral mandrel die for polymer pipe extrusion. The influences of both geometrical dimensions of spiral mandrel and processing parameters upon the stresses and deformations of the die body were investigated. The simulated results are very useful as guidance for the die design. The following conclusions were obtained:

1. Large thermal deformation is found in the forming section of the extrusion die with a maximum value of $5.94 \mathrm{~mm}$. It is suggested that the ceramic heaters at the die surfaces should be connected using spring joints to prevent them being broken by the thermal expansion. In the spiral section, the gaps between each spiral groove should be strong enough to resist the pressure induced deformation when designing the die mandrel. The maximum stress of $640.2 \mathrm{MPa}$ is found at the inlet of the spiral grooves.

2. Both the decrease of the end radius of mandrel $\left(R_{3}\right)$ and increase of helix angle $(\alpha)$ can lead to lower maximum stress in the die body and the deformation at the die orifice. A suitable initial depth of spiral groove is required to balance the maximum stress and deformation of the die body. The increase of mass flow rate will result in a significant increase of both stress and deformation of the die body.

3. The variation patterns of the essential characteristics obtained by simulation are found to be consistent with those measured by experiment, which demonstrate that the developed coupled thermal-structural model can effectively predict the elastic deformations and stresses in the spiral mandrel die.

4. The newly developed coupled thermal-structural modelling framework can be further developed to include the transit behaviour, polymer melt flow and thermalmechanical fatigue capability for the spiral mandrel die.

Funding The authors would like to acknowledge the ASTUTE 2020 (Advanced Sustainable Manufacturing Technologies) operation supporting manufacturing companies across Wales, which has been part-funded by the European Regional Development Fund through the Welsh Government and the participating Higher Education Institutions. 
Open Access This article is licensed under a Creative Commons Attribution 4.0 International License, which permits use, sharing, adaptation, distribution and reproduction in any medium or format, as long as you give appropriate credit to the original author(s) and the source, provide a link to the Creative Commons licence, and indicate if changes were made. The images or other third party material in this article are included in the article's Creative Commons licence, unless indicated otherwise in a credit line to the material. If material is not included in the article's Creative Commons licence and your intended use is not permitted by statutory regulation or exceeds the permitted use, you will need to obtain permission directly from the copyright holder. To view a copy of this licence, visit http://creativecommons.org/licenses/by/4.0/.

\section{References}

1. Perdikoulias J, Vlcek J, Svabik J (2005) Application of 3D flow simulation towards blow film die optimization. InFachtagung: TAPPI PLACE Conference 25:29

2. Shetty S (2010) Estimates for the pressure and thermal distortions of coating dies for use in design and simulation. Dissertation, Rochester Institute of Technology

3. Kubík P (2008) A comparison of results from 2D and 3D approaches for spiral mandrel die flow simulation. Dissertation, Tomas Bata University in Zlín

4. Hopmann C, Michaeli W (2016) Extrusion dies for plastics and rubber, 4th edn. Hanser Publishers, Munich

5. Lee YS, Lee JH, Choi JU, Ishikawa T (2002) Experimental and analytical evaluation for elastic deformation behaviors of cold forging tool. J Mater Process Technol 127(1):73-82

6. Long H (2006) Quantitative evaluation of dimensional errors of formed components in cold backward cup extrusion. J Mater Process Technol 177(1-3):591-595

7. Wang Q, Smith DE (2007) Analysis of the fluid-structure interaction in the optimization-based design of polymer sheeting dies. J Appl Polym 103(6):3994-4004

8. Assaad W, Geijselaers HJ (2011) Coupled analysis of material flow and die deflection in direct aluminum extrusion. InAIP Conference Proc 1315(1):495-497

9. Kouzilos GN, Markopoulos AP, Manolakos DE (2015) Manufacturing and modeling of an extrusion die spider head for the production of HDPE tubes. J Manuf Technol Res 6(1-2):1-15

10. Kouzilos GN, Seretis GV, Provatidis CG, Manolakos DE (2017) Design of polymer extrusion dies using finite element analysis. In: Qamar SZ (ed) Extrusion of Metals, Polymers and Food Products. IntechOpen, London, pp 181-196

11. Pepelnjak T, Milutinović M, Plančak M, Vilotić D, Randjelović S, Movrin D (2016) The influence of extrusion ratio on contact stresses and die elastic deformations in the case of cold backward extrusion. Strojniški Vestnik 62(1):41-50

12. Akhtar SS, Arif AF (2010) Fatigue failure of extrusion dies: effect of process parameters and design features on die life. J Fail Anal Prev 10(1):38-49

13. Behrens BA, Bouguecha A, Raedt HW, Hadifi MS (2010) Numerical investigations on the fatigue failure of forging tools due to thermo-mechanical cyclic loading. Int J Mater Form 3(1): 339-342

14. Ahn SH, Kim TH, Kim BM, Choi JC (1997) A study on the prediction of fatigue life in an axi-symmetric extrusion die. J Mater Process Technol 71(3):343-349

15. Pedersen $T \varnothing$ (2000) Numerical studies of low cycle fatigue in forward extrusion dies. J Mater Process Technol 105(3):359-370

16. Yang LQ, Lv QQ, Zhang HM, Zhu CH, Wang WZ (2018) Structural strength and service life of the extrusion forming die for agricultural engine piston heads. Strength Mater 50(1):107-115

17. Lin Z, Juchen X, Xinyun W, Guoan H (2003) Optimization of die profile for improving die life in the hot extrusion process. J Mater Process Technol 142(3):659-664

18. Kwan CT, Wang CC (2011) An optimal pre-stress die design of cold backward extrusion by RSM method. Struct Longev 5(1):2532

19. Zhao G, Chen H, Zhang C, Guan Y (2013) Multiobjective optimization design of porthole extrusion die using Pareto-based genetic algorithm. Int J Adv Manuf Technol 69(5-8):1547-1556

20. Bingöl S, Ayer Ö, Altinbalik T (2015) Extrusion load prediction of gear-like profile for different die geometries using ANN and FEM with experimental verification. Int J Adv Manuf Technol 76(5-8): 983-992

21. Nie Y, Hao J, Lin YJ, Sun W (2018) 3D simulation and parametric analysis of polymer melt flowing through spiral mandrel die for pipe extrusion. Adv Polym Technol 37(8):3882-3895

22. Wu PY, Huang LM, Liu TJ (1995) A simple model for heat transfer inside an extrusion die. Polym Eng Sci 35(21):1713-1724

23. Denizart O, Vincent M, Agassant J (1995) Thermal stresses and strains in injection moulding: experiments and computations. $\mathrm{J}$ Mater Sci 30(2):552-560

24. Jansen K, Shakib F, Hughes TJR (1992) Fast projection algorithm for unstructured meshes. In: Atluri SN (ed) Computational Nonlinear Mechanics in Aerospace Engineering. AIAA, Washington DC, pp 175-204

25. Instruments N (1998) Strain Gauge Measurement-A Tutorial. http://elektron.pol.lublin.pl/elekp/ap_notes/NI_AN078_Strain_ Gauge_Meas.pdf

Publisher's note Springer Nature remains neutral with regard to jurisdictional claims in published maps and institutional affiliations. 